\title{
Investigating the effect of passes number on microstructural and mechanical properties of the Al2024/SiC composite produced by friction stir processing
}

\author{
D. Ghanbari*, M. Kasiri Asgharani*, K. Amini** \\ *Department of Materials Science, Najaf Abad Branch, Islamic Azad University, Isfahan, Iran \\ **Department of Mechanical Engineering, Tiran Branch, Islamic Azad University, Isfahan, Iran \\ cross $^{\text {ref }}$ http://dx.doi.org/10.5755/j01.mech.21.6.12227
}

\section{Introduction}

The problems of manufacturing metal matrix composites via the melting methods lead to the use of the innovative ways in the solid-state methods [1]. Friction stir welding as a solid-state technique was introduced by The Welding Institute (TWI) in 1991. In this joining method, sever plastic deformation occurred in a distinct strain rate and high temperature. The FSP microstructure, obtained due to the occurrence of dynamic recrystallization, consists of stir zone (SZ) as a modified structure with co-axial grains, and thermos-mechanical affected zone (TMAZ) in which the strain partially happens and the peak temperature in this area is less than that in the SZ area. After that, the heat affected zone (HAZ) is the only experienced thermal cycle due to the welding process and no deformation occurred in this area. Finally, it reached to the base metal [2]. In 2003, Mishra [3] used FSP for the first time in order to join ceramic particles on the surface of aluminum. He could make a composite layer of AA5083/SiC with $200 \mu \mathrm{m}$ thickness on the surface of aluminum by using FSP. From then on, many researches were carried out by various scholars on the impact of the number of friction stir process passes on aluminum alloys [4-7]. It was shown that mechanical properties such as hardness and wear resistance are improved due to the increase in the number of passes. This improvement is a consequence of a more uniform strengthening particles distribution as a result of increasing the number of friction stir passes. On the other hand, friction stir welding is a thermo-mechanical process in which the work-piece is exposed to the heat treatment cycle. The 2024-series aluminum is a precipitation hardening type and its hardness suffered from sharp declines in the SZ region regarding the dissolution and coarsening of precipitates during friction stir welding [8-10]. Therefore, in this study, the Al2024 / SiC composite is produced via the friction stir process and the effects of the FSP passes are investigated. Moreover, the interaction of the hard SiC particles with the structure, changing the shape, size and distribution of particles and the interaction of each of these factors with the hardness and wear behavior of the Al2024 / SiC composite are studied.

\section{Experimental detail}

\subsection{Materials}

A12024 aluminum alloy in T351 condition was used in this research. The chemical composition of the alloy is given in Table 1. Samples with dimensions of $300 \times 200 \times 8 \mathrm{~mm}$ and nano-scale $\mathrm{SiC}$ particles with average diameter of $50 \mathrm{~nm}$ were selected in the present study.

Table 1

Chemical composition of the Al2024 alloy (Wt\%)

\begin{tabular}{|c|c|c|c|c|c|c|c|c|}
\hline $\mathrm{Si}$ & $\mathrm{Fe}$ & $\mathrm{Cu}$ & $\mathrm{Mn}$ & $\mathrm{Mg}$ & $\mathrm{Zn}$ & $\mathrm{Cr}$ & $\mathrm{Ti}$ & $\mathrm{Al}$ \\
\hline 0.11 & 0.31 & 4.43 & 0.6 & 1.47 & 0.05 & 0.01 & 0.01 & $\mathrm{Bal}$ \\
\hline
\end{tabular}

\subsection{Friction stir processing (FSP)}

FSP was carried out on a reinforcement vertical milling machine. The traverse speed was kept $25 \mathrm{~mm} / \mathrm{s}$ with the pin rotation speed of $1000 \mathrm{rpm}$. The tilt angle was 3 degrees in all the passes. Various samples of Al2024/SiC were processed with different FSP passes. The details of each process are presented in Table 2 . A time interval between each pass was considered, so that the samples could reach the room temperature. The nano-scale $\mathrm{SiC}$ particles were packed in a square groove of $2.5 \mathrm{~mm}$ width and $1 \mathrm{~mm}$ depth cut on the aluminum matrix in the center line of each sample. The groove opening was initially closed by means of a tool which has shoulder without pin. The H13 tool steel with the hardness of 55 HRC was chosen for FSP. The obtained results from pervious researches [11-12] showed that the square pin with the pin diameter to shoulder diameter ratio of $1 / 3$ yielded the best results. In this regard, the square pin with the shoulder diameter of $18 \mathrm{~mm}$, pin diameter of $6 \mathrm{~mm}$, and pin length of $2.5 \mathrm{~mm}$ was used in this research as shown in Fig. 1.

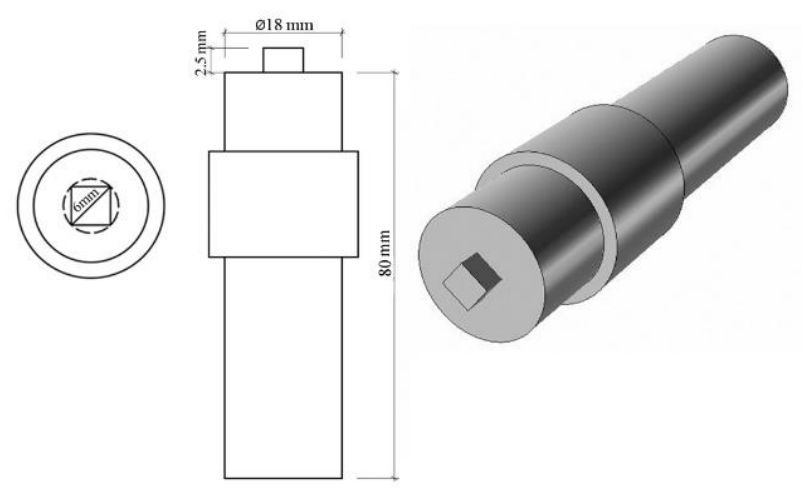

Fig. 1 Schematic of the tool pin

\subsection{Characterization}

Microhardness tests were performed at the cross section of the samples with a load of $100 \mathrm{~g}$ and duration of 
$10 \mathrm{~s}$ using a Vickers digital microhardness tester. Microstructural observations were conducted at the cross section of the samples, which had been mechanically polished and etched with tint etch reagent $(4 \mathrm{~g} \mathrm{~K} 2 \mathrm{MnO} 4,1.5 \mathrm{~g} \mathrm{NaOH}$, and $100 \mathrm{ml} \mathrm{H} 2 \mathrm{O}$ ) by employing optical microscopy (OM). Field-emission scanning electron microscopy (FE-SEM) was also used for measuring the nano-scale particles size and investigating the distribution of precipitations. The worn morphology of the composites surface was evaluated by scanning electron microscopy (SEM) to discuss the wear mechanism.

\subsection{Wear resistance test}

Wear test was performed on a linearly reciprocating ball-on-fiat sliding wear tester as per the ASTM: G13395 standard. The wear tests were carried out in air at room temperature and a humidity of $40-50 \%$ with a constant load $(20 \mathrm{~N})$ and sliding speed $(0.14 \mathrm{~m} / \mathrm{s})$. The pin ball was made of AISI 5200 steel with a hardness of 64 HRC. The diameter of the pin ball was $5 \mathrm{~mm}$. At intervals of 100 meters, the samples were cleaned by ethanol and the wear volume loss was measured. The average of the measured values represented the mean wear volume losses of the samples.

Table 2

The process conditions

\begin{tabular}{|c|l|}
\hline Sample Number & \multicolumn{1}{|c|}{ Number of Passes } \\
\hline 1P & Sample produced by one FSP passes \\
\hline 2P & Sample produced by two FSP passes \\
\hline 3P & Sample produced by three FSP passes \\
\hline 4P & Sample produced by four FSP passes \\
\hline
\end{tabular}

\section{Experimental results and discussion}

\subsection{Investigation of microstructure and grain size}

Fig. 2 shows the microstructure and grain size of the base metal and the sample produced by four FSP passes. The microstructure of the base metal with elongated grains in a direction parallel to the rolling direction is shown in Fig. 2, a. The four areas which are created during FSP are clearly and distinctly displayed in Fig. 2, b. Accordingly, the base metal and the HAZ are depicted with elongated grains without any change in the grain size. In the TMAZ, on the other hand, the stirring slightly occurs and causes the formation and rotation of the grains. The SZ presents a microstructure with dynamically recrystallized fine equiaxed grains. The stir zone is shown in two forms: the SZ-b area which is formed between the first to the third passes and the SZ-a area which is created in the fourth pass. The formation of the SZ-b area is related to the slight shift of the tool pin and its lack of full compliance in various passes. The agglomeration of the nano-scale particles is one of the limitations in the FSP method. Sharifitabar and colleagues [5] documented that the increase in the number of passes causes the improvement of particles distribution. However, the agglomerated nano-scale particles of $\mathrm{SiC}$ are observed in the interface of the SZ area. Fig. 2, c shows the microstructure of the SZ-a region in sample $4 p$ with fine equiaxed grains. Some researchers $[4-6,13]$ reported that the formation of microstructure with fine equiaxed grains is related to the creation of dynamic recrystallization. Macnelley et al. [2] suggested various mechanisms for dynamic recrystallization during the thermo-mechanical processes such as dynamic recovery (DVR), discontinuous dynamic recrystallization (DDRX), and geometric dynamic recrystallization (GDR). Bauri et al. [6] declared that the grain size decreases with increasing the number of passes due to dynamic recovery. The presence of dislocation sources (i.e. grain boundary, interface of the matrix and particles, plastic deformation) makes the matrix structure with a high density of dislocations. Dynamic recovery in metals with high energy in arranged atom defect (e.g. aluminum) makes dislocation arrangement in the form of the sub-grains. Yadav et al. [13] showed that when the sub-grains join the dislocation, they change the low angle grain boundaries and these grain boundaries can alter the high-angle grain boundaries due to the slip of dislocations.

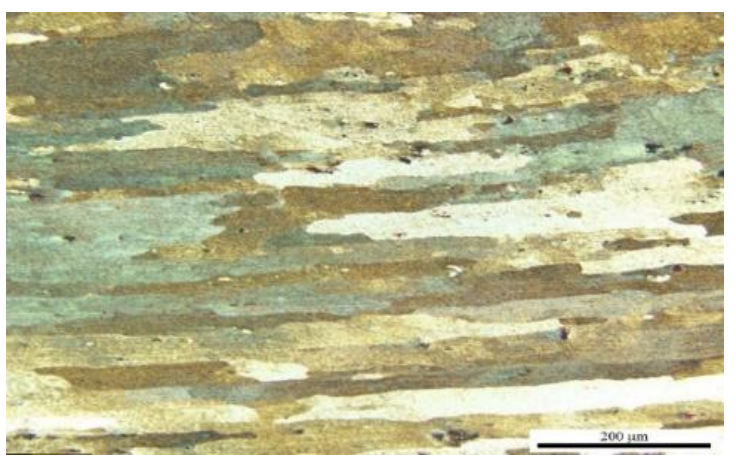

a

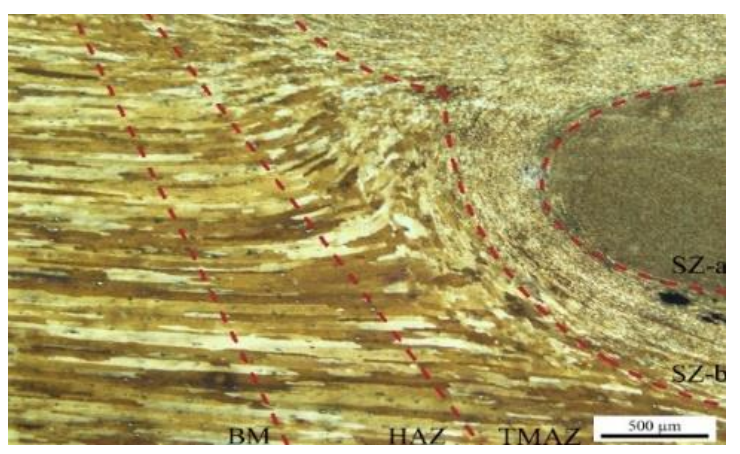

$\mathrm{b}$

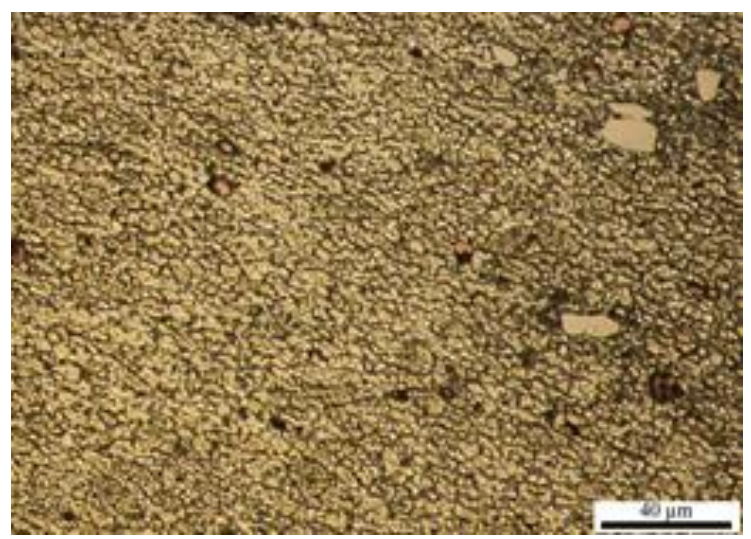

Fig. 2 Grain size and microstructure of: a - the base metal; $\mathrm{b}$ - the $4 \mathrm{p}$ sample; $\mathrm{c}$ - the $\mathrm{SZ}$-a region of the $4 \mathrm{p}$ sample 


\subsection{Evaluation of precipitations and intermetallic compounds}

Fig. 3 shows the FE-SEM images of the base metal and the SZ area in the $2 p$ and $4 p$ samples. As shown in Fig. 3, a, three kinds of intermetallic compounds can be distinguished in the base metal. These compounds consist of the S-phase as circular intermetallic compounds of $\mathrm{Al} 2 \mathrm{CuMg}$, the $\Theta$-phase as coarse intermetallic compounds of $\mathrm{Al} 2 \mathrm{Cu}$, and irregular-shapes of intermetallic compounds of $\mathrm{Al}-\mathrm{Cu}-\mathrm{Fe}-\mathrm{Mn}$. The EDX spectra of the intermetallic compounds and nano-scale particles of $\mathrm{SiC}$ within in the structure are displayed in Fig. 4. Bousquet et al. [10] showed the presence of the S-phase and Al-Cu-Fe-Mn compounds in their researches. Fig. $4, \mathrm{~b}$ and $4 \mathrm{c}$ show the $\mathrm{SZ}$ area of the $2 \mathrm{p}$ and $4 \mathrm{p}$ samples, respectively. From these figures, it is clear that the nano-scale particles of $\mathrm{SiC}$ are uniformly distributed in the matrix with increasing the number of passes. However, agglomerated SiC particles with micron size are also observed in the $2 \mathrm{p}$ and $4 \mathrm{p}$ sam-

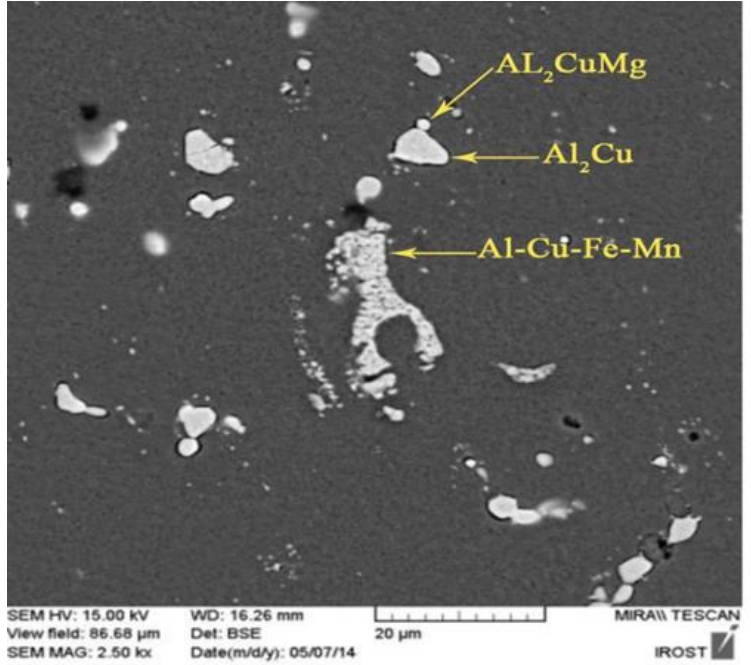

a

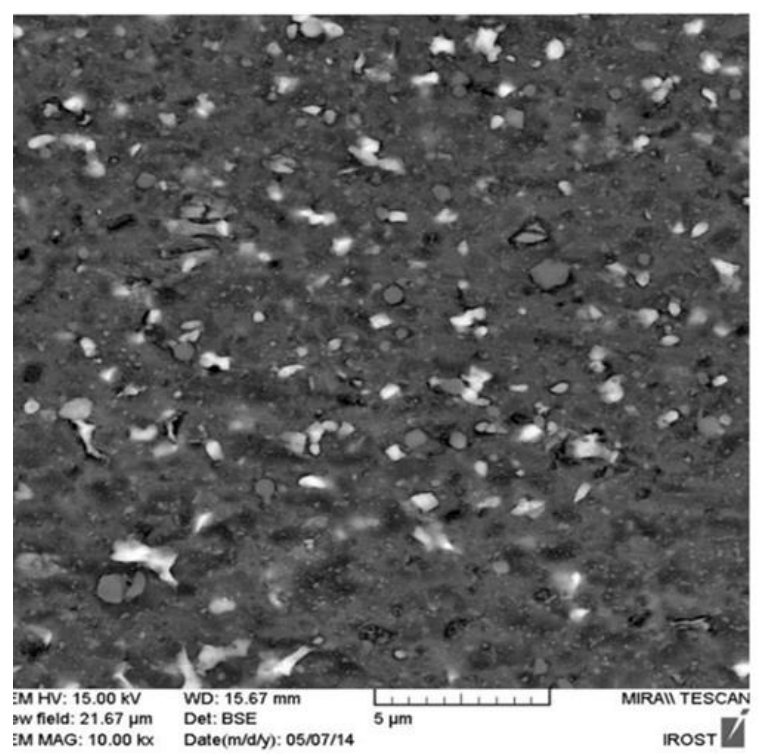

c ples. Shafiei et al. [7] also reported the presence of the nano-scale particles of $\mathrm{Al}_{2} \mathrm{O}_{3}$ as agglomerated particles in the matrix after four passes. As shown in Fig. 4, b and 4, c, the S-phase particles in the SZ region are formed with a higher density than the base metal. Fig. 4, d shows the high magnification image of the SZ region in the $4 p$ sample. According to this figure, lots of S-phase compounds are formed within the interface of the $\mathrm{Al}-\mathrm{Cu}-\mathrm{Fe}-\mathrm{Mn}$ compounds and the matrix. Genevois et al. [8] reported that the S-phase precipitations are created in the matrix due to the dissolution of the GP regions and re-precipitation during thermo-mechanical process in the Al2024 alloy. In addition, the difference between thermal contraction coefficient of the $\mathrm{Al}-\mathrm{Cu}-\mathrm{Fe}-\mathrm{Mn}$ compounds and the matrix resulted in an interface with a high density of dislocations. Genevois et al. [9] also presented that the dislocations can act as a rapid diffusion route in the precipitation process and that they cause the increase of the precipitation kinetic of the Sphase.

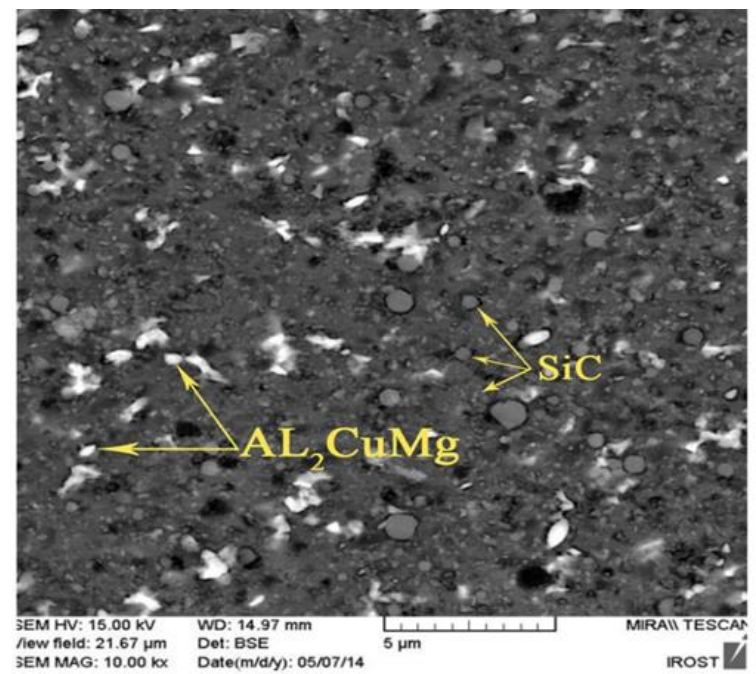

b

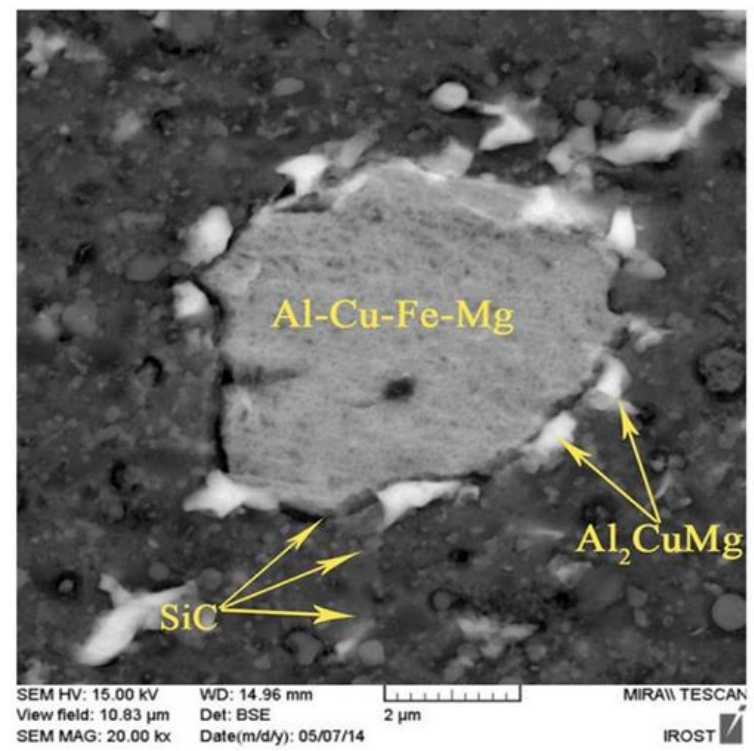

d

Fig. 3 FE-SEM images of microstructure and particles dispersion in: a - the base metal; $b-$ the $2 p$ sample; $c-$ the $4 p$ sample; $d$ - high magnification view of (c) 

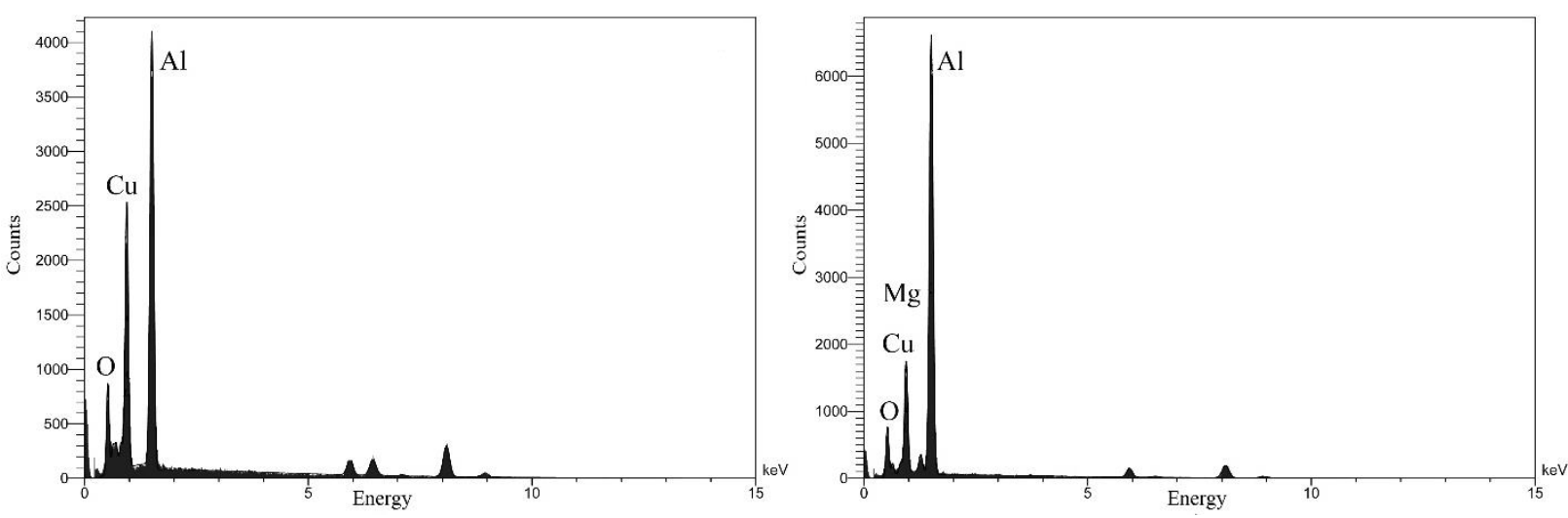

a
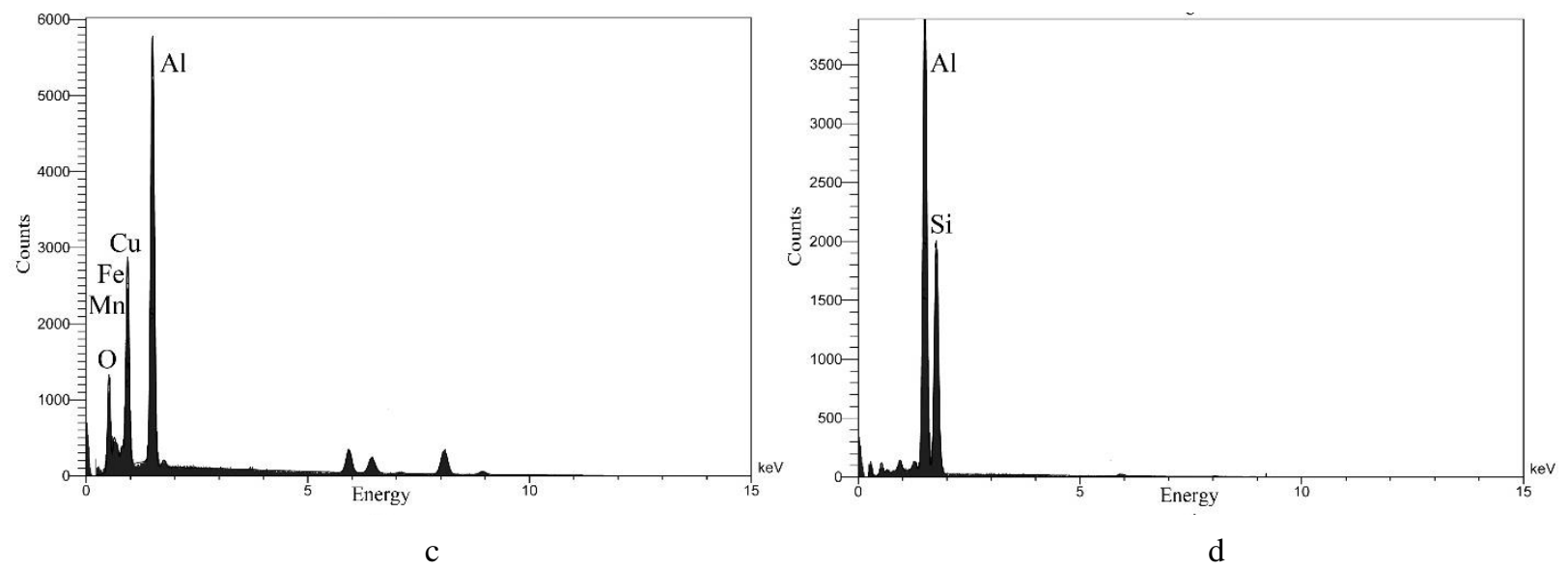

Fig. 4 EDX analysis of the particles: $\mathrm{a}-\mathrm{Al}_{2} \mathrm{Cu}$; b - $\mathrm{Al}_{2} \mathrm{CuMg}$; $-\mathrm{Al}-\mathrm{Cu}-\mathrm{Fe}-\mathrm{Mn}$; d - SiC

\subsection{Hardness}

Fig. 5 displays the hardness profile of the $1 p$ to $4 p$ samples. As can be seen in Fig. 5, the hardness of the $1 \mathrm{p}$ sample in the SZ region, rather than the base metal, increases about $10 \mathrm{HV}$ and consequently reaches to $120 \mathrm{HV}$. In the $2 \mathrm{p}, 3 \mathrm{p}$, and $4 \mathrm{p}$ samples, hardness decreases with increasing the number of passes, so that the hardness of the composite samples is reduced rather than the hardness of the base metal after the fourth pass. In addition, it is clear that the width of the SZ region increases with increasing the number of passes. This can be attributed to the absence of full coincidence in various passes. Some researchers [5-6] showed that the ceramic particles are uniformly distributed in the matrix due to increase in the number of passes. This phenomenon causes the increase of hardness. However, in the produced composite in this research, the obtained hardness results show otherwise. Accordingly, in order to provide a better explanation of this matter, it is attempted to describe the strength mechanisms in the produced composite by the results obtained by other researchers. In this regard, Mazaheri et al. [14] explained that the possible strength mechanisms are categorized into four groups: (a) the Orowan mechanism, (b) work hardening due to the strain of the mismatch between elastic particles and the matrix, (c) quench hardening as a result of dislocations because of the difference between thermal contraction ratio of the particles and the matrix, (d) grain and substructural strengthening. Zahmatkesh et al. [15] reported that the increase of hardness in Al2024-T4 during the FSP method is related to the refinement of the grains in the SZregion. However, Zahmatkesh and Enayati [16] documented that the increase in hardness of the produced composite of $\mathrm{Al} 2024 / \mathrm{Al}_{2} \mathrm{O}_{3}$ is dependent on the uniform distribution of the $\mathrm{Al}_{2} \mathrm{O}_{3}$ particles in the matrix alloy. It is worth mentioning that the Al2024-T351 alloy is a kind of precipitation hardening alloy and that with increasing the number of passes, the heat input increases. As a result, the increasing of the heat input leads to change in type, size, and distribution of strength precipitation within the alloy matrix. These alterations in microstructure can affect the value of hardness. According to references 14-16, the presence of the GP zones is the main reason for the strength in the Al2024T351 alloy. Additionally, Genevois et al. [8] reported that the most important phenomenon of precipitation in the $\mathrm{Al} 2024$ alloy during the FSP method is related to the dissolution of the GP zones and the S-phase particle precipitations. The type of interface and the size of the S-phase particles can affect the increase or decrease of hardness. According to Fig. 3, it is explained that the presence of coarse compounds is resulted from the dissolution of the GP zones and their re-precipitation in the matrix. The presence of coarse compounds in the matrix causes the severe reduction of hardness, so that other mechanisms of increase of hardness such as Orowan and refine-structure cannot compensate for the reduction of hardness. On the other hand, the increasing of the passes number causes the increase of the heat input, the intensification of dissolution of GP-zones, and the precipitation of coarse S-phase compounds. 


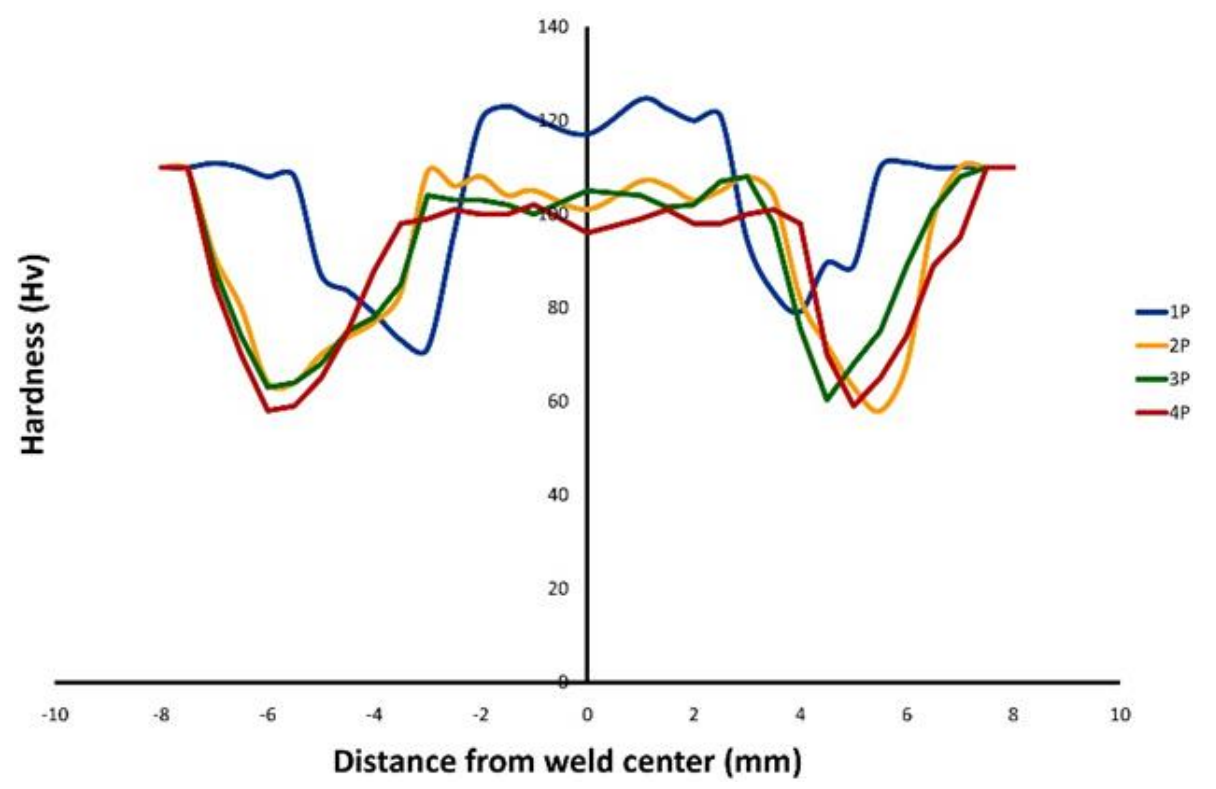

Fig. 5 Vickers hardness profile of the composite samples

\subsection{Wear properties}

Fig. 6 shows the relationship between weight loss and the sliding distance of the as-processed samples. As can be seen in this figure, the wear weight loss increases with the sliding distance. The weight loss sharply increases at the initial stage and then decreases with increasing the sliding distance. According to Fig. 6, it can be concluded that, generally, the wear feature is a plain (mild) type. Fig. 7 shows the SEM micrographs of the worn surface of the samples. As can be seen, the wear mechanism of the base metal is adhesive wear. The presence of multi-layer adhesive regions with high depth and the high amount of particles on the matrix can prove the adhesive wear mechanism. Additionally, it is obvious that the wear mechanism in the composite samples is changed from severity wear adhesive mechanism to plain wear adhesive mechanism with increasing the number of passes. In this regard, the multi-layer adhesive regions are altered to the single-layer adhesive regions and the value of particles severity decreases. In addition, the wear causes the reduction of the depth of the deformed sub-layers. Raaft et al. [17] reported that the presence of ceramic particles in the matrix is one of the factors of wear mechanism. In like manner, Alidokht et al. [18] also documented that the peeled abrasive particles from the surface which are locked between surface and pin are considered as the abrasive particles. These particles increase the wear of the surface with the scratch mechanism. As discussed previously, the $\mathrm{SiC}$ particles cannot be a factor to increase wear in the Al2024/SiC composite. However, it can be claimed that the presence of the $\mathrm{SiC}$ particles in the matrix as the third-phase abrasive particles increases the tendency to wear of the scratch. Additionally, they cause the decrease of abrasive particles value on the surface and also reduce the depth of deformed layers. Consequently, the wear behaviour goes toward the abrasive wear.

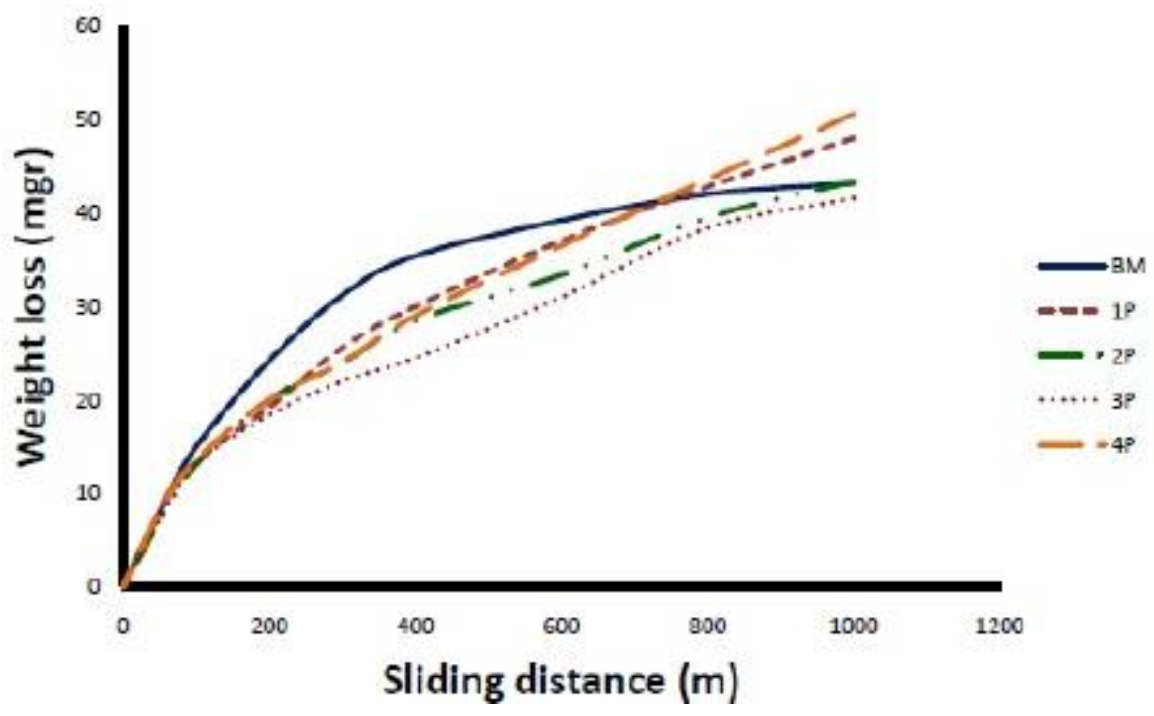

Fig. 6 Variation of weight loss with sliding distance 


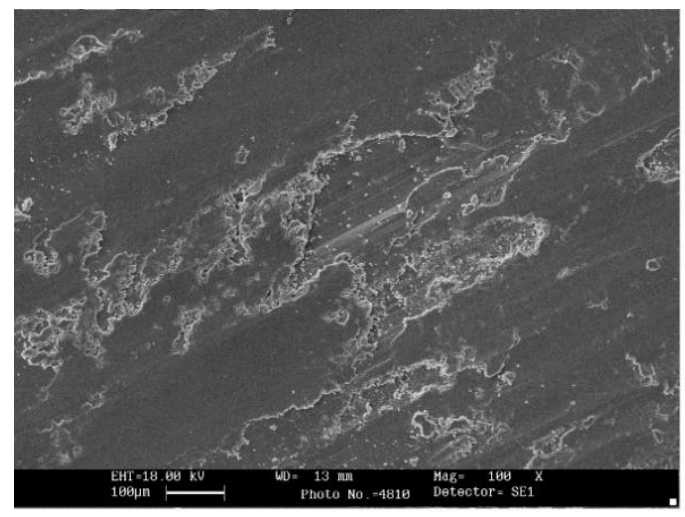

$\mathrm{a}$

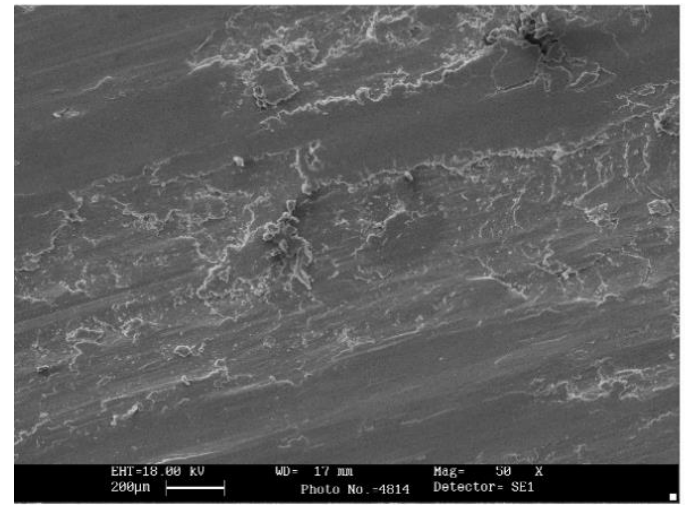

c

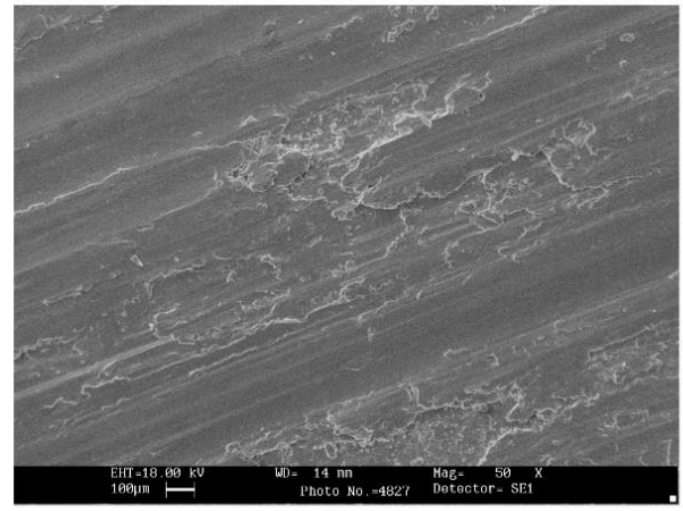

e

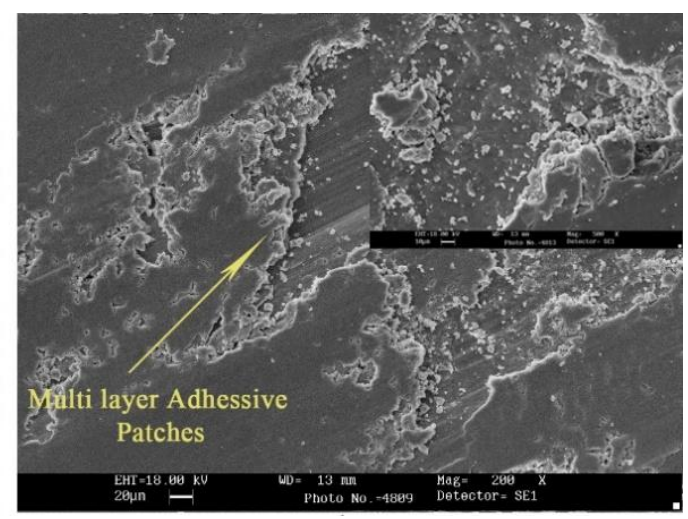

b

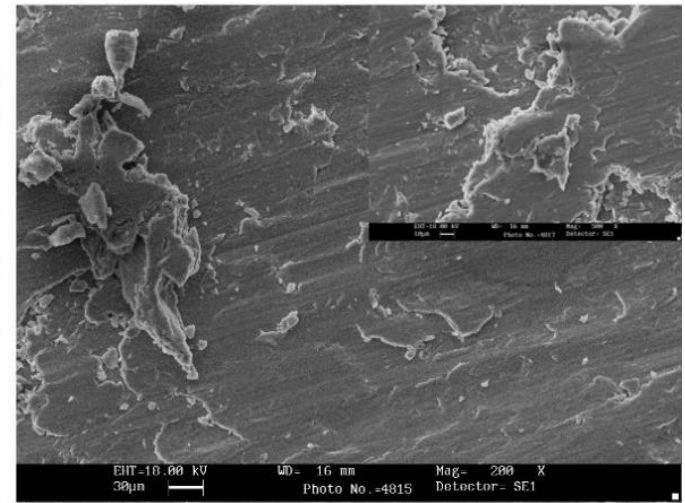

d

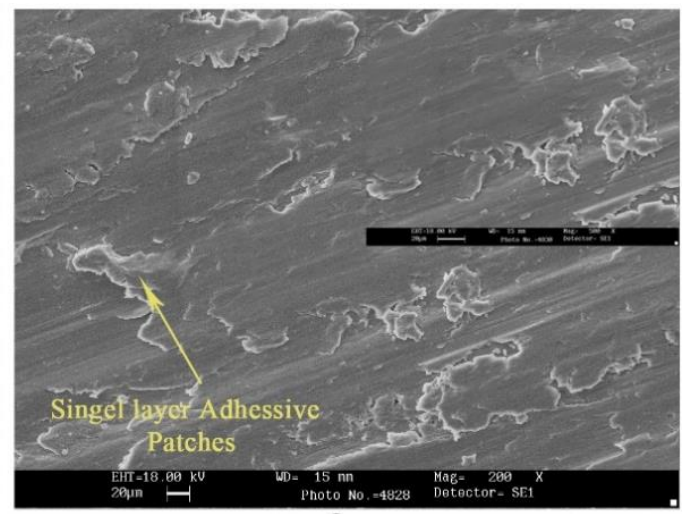

f

Fig. 7 SEM micrographs of the worn-out track of: $a, b$ - the base metal; $c, d$ - the 2 psample; e, $f-4 p$

\section{Conclusion}

1. The nano-scale particles of SiC were uniformly distributed within the structure during the FSP method. However, the performing of four passes caused the formation of some agglomerated particles within the structure.

2. Hardness of the nano-scale composite of the $\mathrm{Al} 2024 / \mathrm{SiC}$ composite was not dependent on the presence of the nano-scale $\mathrm{SiC}$ particles. It was dependent on the condition of precipitation strengthening.

3. The increase of passes caused the increase of the heat input and consequently, the formation of coarse compounds of the S-phase within the structure, leading to the decrease of hardness.

4. The $2 p$ and $4 p$-composite samples showed an almost the same wear behaviour compared to the base metal. But the intensity of adhesive mechanism was re- duced with increasing the number of passes and the tendency to the abrasive mechanism was also increased.

\section{References}

1. Hong, J.; Kim, H.M.; Huh, D.; Suryanarayana, C.; Chun, B.S. 2003. Effect of clustering on the mechanical properties of $\mathrm{SiC}$ particulate reinforced aluminium alloy 2024 metal matrix composites, Materials Science and Engineering A A347: 198-204. http://dx.doi.org/10.1016/S0921-5093(02)00593-2.

2. McNelley, T.R.; Swaminathan, S.; Su, J.Q. 2008. Recrystallization mechanisms during friction stir welding/processing of aluminium alloys, Scripta Materialia 58: 349-354.

http://dx.doi.org/10.1016/j.scriptamat.2007.09.064.

3. Mishra, R.S.; Ma, Z.Y.; Charit, I. 2003. Friction stir processing: a novel technique for fabrication of surface 
composite, Materials Science and Engineering A 341: 307-310. http://dx.doi.org/10.1016/S0921-5093(02)00199-5.

4. Dolatkhah, A.; Golbabaei, P.; Besharati Givi, M.K.; Molaiekiya, F. 2012. Investigating effects of process parameters on microstructural and mechanical properties of A15052/SiC metal matrix composite fabricated via friction stir processing, Materials and Design 37: 458-464. http://dx.doi.org/10.1016/j.matdes.2011.09.035.

5. Sharifitabar, M.; Sarani, A.; Khorshahian, S.; Shafiee Afarani, M. 2011. Fabrication of 5052Al/ Al2O3 nanoceramic particle reinforced composite via friction stir processing route, Materials and Design 32: 4164-4172.

http://dx.doi.org/10.1016/j.matdes.2011.04.048.

6. Bauri, R.; Yadav, D.; Suhas, G. 2011. Effect of friction stir processing (FSP) on microstructure and properties of $\mathrm{Al}-\mathrm{TiC}$ in situ composite, Materials Science and Engineering A 528: 4732-4739.

http://dx.doi.org/10.1016/j.msea.2011.02.085.

7. Shafiei-Zarghani, A.; Kashani-Bozorg, S.F.; ZareiHanzaki, A. 2009. Microstructures and mechanical properties of $\mathrm{Al} / \mathrm{Al} 2 \mathrm{O} 3$ surface nano-composite layer produced by friction stir processing, Materials Science and Engineering A 500: 84-91.

http://dx.doi.org/10.1016/j.msea.2008.09.064.

8. Genevois, C.; Deschamps, A.; Denquin, A.; Doisneau-cottignies. 2005. Quantitative investigation of precipitation and mechanical behaviour for AA2024 friction stir welds, Acta Materialia 53: 2447-2458. http://dx.doi.org/10.1016/j.actamat.2005.02.007.

9. Genevois, C.; Deschamps, A.; Denquin, A.; Doisneau-cottignies. 2005. Quantitative investigation of precipitation and mechanical behaviour for AA2024 friction stir welds, Acta Materialia 53: 2447-2458. http://dx.doi.org/10.1016/j.actamat.2005.02.007.

10. Bousquet, E.; Poulon-Quintin, A.; Puiggali, M.; Devos, O. 2011. Relationship between microstructure, microhardness and corrosion sensitivity of an AA 2024-T3 friction stir welded joint, Corrosion Science 53: 3026-3034. http://dx.doi.org/10.1016/j.corsci.2011.05.049.

11. Elangovan, K.; Balasubramanian, V. 2008. Influences of tool pin profile and welding speed on the formation of friction stir processing zone in AA2219 aluminium alloy, Journal of Materials Processing Technology 200: 163-175.

http://dx.doi.org/10.1016/j.jmatprotec.2007.09.019.

12. Elangovan, K.; Balasubramanian, V. 2008. Influences of tool pin profile and tool shoulder diameter on the formation of friction stir processing zone in AA6061 aluminium alloy, Materials and Design 28: 362-373.

http://dx.doi.org/10.1016/j.matdes.2007.01.030.

13. Yadav, D.; Bauri R. 2011. Processing, microstructure and mechanical properties of nickel particles embedded aluminium matrix composite, Materials Science and Engineering A 528: 1326-1333.

http://dx.doi.org/10.1016/j.msea.2010.10.035.
14. Mazaheri, Y.; Karimzadeh, F.; Enayati, M.H. 2011. A novel technique for development of A356/A12O3 surface nanocomposite by friction stir processing, Journal of Materials Processing Technology 211: 1614-1619.

http://dx.doi.org/10.1016/j.jmatprotec.2011.04.015.

15. Zahmatkesh, B.; Enayati, M.H.; Karimzadeh, F. 2010. Tribological and microstructural evaluation of friction stir processed Al2024 alloy, Materials and Design 31: 4891-4896. http://dx.doi.org/10.1016/j.matdes.2010.04.054.

16.Zahmatkesh, B.; Enayati, M.H. 2010. A novel approach for development of surface nanocomposite by friction stir processing, Materials Science and Engineering A 527: 6734-6740.

http://dx.doi.org/10.1016/j.msea.2010.07.024.

17. Raaft, M.; Mahmood, T.S.; Zakaria, H.M.; Khalifa, T.A. 2011. Microstructural, mechanical and wear behaviour of A390/graphite and A390/A12O3 surface composites fabricated using FSP, Materials Science and Engineering A A528: 5741-5746. http://dx.doi.org/10.1016/j.msea.2011.03.097.

18. Alidokht, S.A.; Abdollah-zadeh, A.; Soleymani, S.; Assadi, H. 2011. Microstructure and tribological performance of an aluminium alloy based hybrid composite produced by friction stir processing, Materials and Design 32: 2727-2733.

http://dx.doi.org/10.1016/j.matdes.2011.01.021.

\section{Ghanbari, M. Kasiri Asgharani, K. Amini}

INVESTIGATING THE EFFECT OF PASSES NUMBER ON MICROSTRUCTURAL AND MECHANICAL PROPERTIES OF THE AL2024/SiC COMPOSITE PRODUCED BY FRICTION STIR PROCESSING

S u m m a r y

In this research, a metal matrix composite (MMC) was fabricated by friction stir processing (FSP) on the surface of 2024 aluminum plate with $50 \mathrm{~nm}$-SiC particles. The effect of the FSP passes number on distribution of the $\mathrm{SiC}$-particles in aluminum matrix, microstructure, microhardness, and wear resistance was investigated. Microstructural evaluations showed the presence of uniform and co-axial grains in microstructure and the desired nanoscale particles distribution within the stir zone (SZ). The agglomerated nano-scale particles were identified in the specimens. Mechanical results showed that the change of type, size, and distribution of the nano-scale particles between the FSP passes decreased the hardness and wear properties with increasing in the number of passes.

Keywords: Metal matrix composite, Friction stir processing, Microstructure, Mechanical properties.

Received May 09, 2015

Accepted September 17, 2015 